\title{
Design and Simulation of Autonomous Anti-Rain Construction Site Cover System
}

\author{
Moses Poloko Molatlhegi, Adamu Murtala Zungeru, Jwaone Gaboitaolelwe, Caspar Lebekwe \\ Department of Electrical, Computer and Telecommunications Engineering, Botswana International University of Science and \\ Technology Private Bag 16, Palapye, Botswana.
}

ORCID: 0000-0003-2412-6559 (Adamu Murtala Zungeru)

\begin{abstract}
Water distribution systems mostly involve laying of pipes with the digging of trenches to lay down water pipes as a significant activity. During rainy seasons, trenches tend to fill-up with rainwater before the said pipes could be laid. This poses a danger to workers and residents due to potential landslides. This paper presents the design and simulation of an autonomous anti-rain construction site cover system (AARCSCS), which automates the process of covering a trench or excavation site when it rains. The system was designed for a water distribution system constructor in BIUST, who experienced flooding of a trench due to heavy rainfall before pipes could be laid. As a result, the project was delayed, and more costs were incurred in dealing with the flooding. The focus was to design a circuit that could interface with a trenchcover mechanism able to extend and retract to cover or uncover dug trenches, hence preventing flooding of the trenches. The designed system is based on a rain-sensor module, a bidirectional 12V DC motor, and a 12V DC dual power supply to achieve complementary motor control. The system was simulated and tested on Proteus and performed well according to the design requirements.
\end{abstract}

Keywords: Anti-Rain; Complementary motor control; Electronic system design; Rain sensor; Trench; Construction site.

\section{INTRODUCTION}

The exponential growth of the world population and continuous improvement of the living standard of people means an increase in the construction scale [1]. The construction industry is one of the sectors that is faced with a lot of challenges due to climate conditions. Wet weather is problematic for numerous construction jobs such as roofing, excavating, and many more outdoor construction activities. Other than it being unsavoury to work in, a weighty downpour can likewise diminish sight for the drivers of vehicles and equipment. It additionally transforms sand into the mud, which stances hazards for the security of labourers [2]. The mud is also heavy. This leads to workers and machines having to exert much more energy to move the same cubic feet of dirt, which is now mud [3].

During the construction phase, certain factors that are beyond the control of the constructors tend to affect the completion of projects and compromise the integrity of structures. One of the most prevalent that is often under-addressed is the flooding of construction sites due to heavy rainfall [1]. The construction industry tends to apply dewatering measures instead of applying preventive measures to stop the flooding of sites completely. Dewatering involves the removal of water from a construction site, which is normally done by pumping or evaporation [4]. One of the strategies used is relying on weather forecasting services to provide mobile alerts and satellite imagery so that constructors can protect material and adjust project schedules on time [5]. Site preparation is vital in response to rain, which entails prompt access to more pumps, covering earthwork with plastic though it does not fully seal the area but minimizes the amount of flooding [6]. BIUST is an institution of higher learning established in 2012 located in Palapye with its campus under construction since it opened its doors [7]. One of the vital structures being constructed is a water distribution system within the campus, which mostly includes digging of trenches to lay down water pipes. These trenches are dug more, especially around students' residences, and during rainy seasons they tend to fill with rainwater before pipes could be laid. This poses a danger to workers due to potential landslides, and it also delays the project. Despite efforts to put ridges along dug trenches to stop runaway water, downpour-rainfall still flooded the trenches.

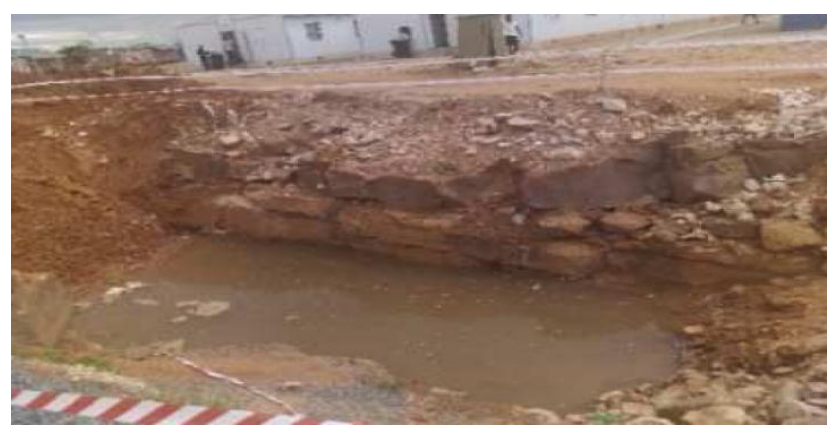

Figure 1: Flooded trench in BIUST

The problem, as mentioned above, required that the constructor finds means to prevent both runway and downpour water from entering the trench when it rains. The main aim of this research was to design a circuit of a system that could cover trenches automatically whenever it starts raining to prevent rainwater accumulation in the trench. The system was intended to detect rainfall and convert that to an electrical signal, which can turn $\mathrm{ON}$ the covering mechanism cycle without human input. 
Besides, it also had to turn $\mathrm{ON}$ uncovering mechanism cycle upon command. The remainder of the paper is organized as follows. Section 2 discusses materials and methods, with emphasis on technical specifications and the design of the autonomous anti-rain construction site cover system. Section 3 presents the results of the working of the system, using different scenarios, while in Section 4 concludes the paper.

\section{MATERIALS AND METHODS}

Autonomous Anti-Rain Construction Site Cover System consists of five subsystems:

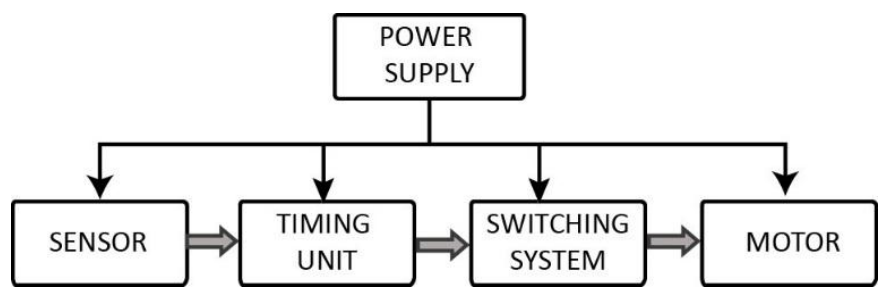

Figure 2: Block diagram showing major parts of the system

\section{Power Supply}

The $12 \mathrm{~V} \mathrm{DC}$ power supply provides the necessary voltage to power the different subsystems as shown in Fig 3. It is a dualtype DC power supply consisting of ground, GND, a positive voltage, VDD, and negative voltage, VEE. This type of power supply is designed with consideration to the half-H bridge circuit that requires a 'negative' voltage to run the motor bidirectionally.

The power supply compromises of two $12 \mathrm{~V}$ batteries placed in series, the mid part being the ground, $0 \mathrm{~V}$. The voltage of the first battery measured between the positive terminal and ground would give a positive voltage, VDD, while the one measured between the ground and negative terminal of the other battery would show a negative voltage, VEE. The DC power supply was used as it is easy to store energy, which is vital for the Autonomous anti-rain construction site cover device to be offgrid since it is meant for the outdoor environment use.

\section{Sensor}

The sensor function is used to detect the presence, absence of rain, and provide the resulting signal to the timer unit. The sensor used is a rain sensor module that functions as a switch that is activated by rainfall. It consists of conductive strips of wire placed at a strategic distance such that current cannot flow due to the high resistance between them. When it rains, raindrops fall on the strips and complete the connection between the wire strips. This completes the circuit, and high output is obtained from the sensor [8]. The rain sensor enables the system to fulfil the design requirement of detecting and converting rain presence into an electrical signal.

\section{Timing Unit}

This circuit turns on a relay for a predetermined amount of time that is beyond the time needed to complete a half cycle (extend or retract) that the trenchcover mechanism used to cover and uncover the trenches. The time required by the trench-cover mechanism to complete a task works based on the size of the trench of which might vary for each users' site location. Hence the time is set to be more than the average calculated time as determined by the trench-cover mechanism designer. The overtimed timer also caters for instances where the trench-cover mechanism is faulty to complete the task within its stipulated time. A 555 timer is used to time and control the switching system that provides power to run the motor for a predetermined amount of time, as shown in Fig 3. The timer is set in a monostable state to provide a one-shot voltage pulse to turn $\mathrm{ON}$ a relay for a calculated amount of time and hence indirectly power $\mathrm{ON}$ the motor [9] [10].

The time to run the motor is calculated using Equation 1 as:

$$
\begin{aligned}
\tau & =1.1 \times R C \\
& =1.1 \times 100 \mathrm{~K} \Omega \times 100000 \mu \mathrm{F} \\
& =1.1 \mathrm{~s}
\end{aligned}
$$

Where; $\mathrm{R}$ is the resistance, $R_{1}$

$C$ is the capacitance, $C_{1}$

The reset pin is controlled by other switches that are part of the switching circuit. They quickly reset the timer when the mechanism has fully retracted or extended, thus saving energy and preventing motor damage. The switch button between the VDD line and BJT is the Override button in Fig 3. Its purpose is to manually activate the mechanism instead of waiting for a signal from the sensor. The button is used for instances where there is still some water on the sensor (remains high), and there is a need to switch $\mathrm{ON}$ the mechanism to uncover the trench.

The timer's role is to turn on a relay switch, which shifts contacts to link the motor circuit to the MOSFETs that supply voltage to drive the motor in a specified direction. A flyback diode connected in parallel to the relay to protect the switching transistor from the high voltage spikes produced when the relay is switched off.

\section{Switching System}

The role of this system is to switch the motor ON or OFF and also control its direction to either forward or backward rotation depending on the task at hand. The switching system is subdivided into sections that control or influence each other to achieve the overall function of motor control, refer to Fig 3. The three subsystems are direct motor control, Indirect motor control, and the Timer reset.

\section{i. Direct motor control}

The circuit controls the direction (forward or backward) in which the motor turns by changing the current flow direction to the motor. The circuit is made up of 2 metal oxide semiconductor field-effect transistors (MOSFETs) connected as a half-H bridge circuit [11] [12] [13]. 
The PMOSFET is connected to the positive power rail VDD operates at a low (active low). When the bridge voltage is low, the PMOSFET switches ON, and current flows from VDD to common, thus turning the motor in the forward direction (covercycle).

The NMOSFET connected to the negative power rail VEE operates at a high (active high). When the bridge voltage is high, current flows from the common to VEE, thus turning the motor in a reverse direction (uncover-cycle) [14].

\section{ii. Indirect motor control}

This switch button controls the direction in which the motor runs when the next signal is received. The two switches, SET and RESET, are connected to pull-down resistors to maintain the state at a low when the buttons are not pressed by the mechanism. The two are connected to an SR flip flop, which goes high when the SET button is pressed and goes low when the RESET button is pressed [15]. The SR flip flop also keeps the memory of the previous output, and only one output pin is used, which is connected as an input to the MOSFET half-H bridge driver circuit. When either the reset or set button is pressed, the timer is switched OFF, hence cutting the voltage supply to the motor. The process is explored in detail on the timer reset circuit.

\section{iii. Timer Reset}

The timer is overset to allow for different trench sizes to be catered for to avoid the mechanism shutting off midway due to insufficient running time. In the same sense, for narrow pits, the mechanism would take a shorter time to complete the halfcycle task (cover/uncover). As such, the motor would still run and get damaged. In order to cater for such eventualities, a timer reset circuit is constructed with the purpose of switching OFF the timer once the half-cycle is completed, which will also switch OFF the motor indirectly as the timer goes OFF.

SET and RESET switch button outputs are connected in parallel to the base of a BC547 bipolar junction transistor for either of them to switch it ON. They are connected via diodes to prevent any backflow of current, which might cause short circuits. The 555-timer reset pin is connected to the collector of the transistor. Therefore, when the BJT is ON, it connects the timer reset pin to the ground. The 555 timer reset pin is active low, hence connecting it to ground switches OFF the 555 timer output.

\section{Motor}

The $12 \mathrm{~V}$ motor is the output of the system that interfaces with the ideal mechanism. Its function is to drive the extending and contracting mechanism, which fulfils the purpose of closing and opening the trench. The circuitry consists of a motor connected in parallel with 4 Light-emitting diodes (LED). The LEDs are operated in pairs to indicate the direction of current flow, which also shows motor rotation. The yellow and green LEDs turn on when the motor rotates clockwise while the red and yellow would light when the motor is turning anticlockwise. The colour coding indicates to the user the direction in which the motor is meant to turn.

Fig 3 shows the complete system circuit diagram, each section connected using terminals. The circuit works in two conditions when it rains and after it stopped raining.

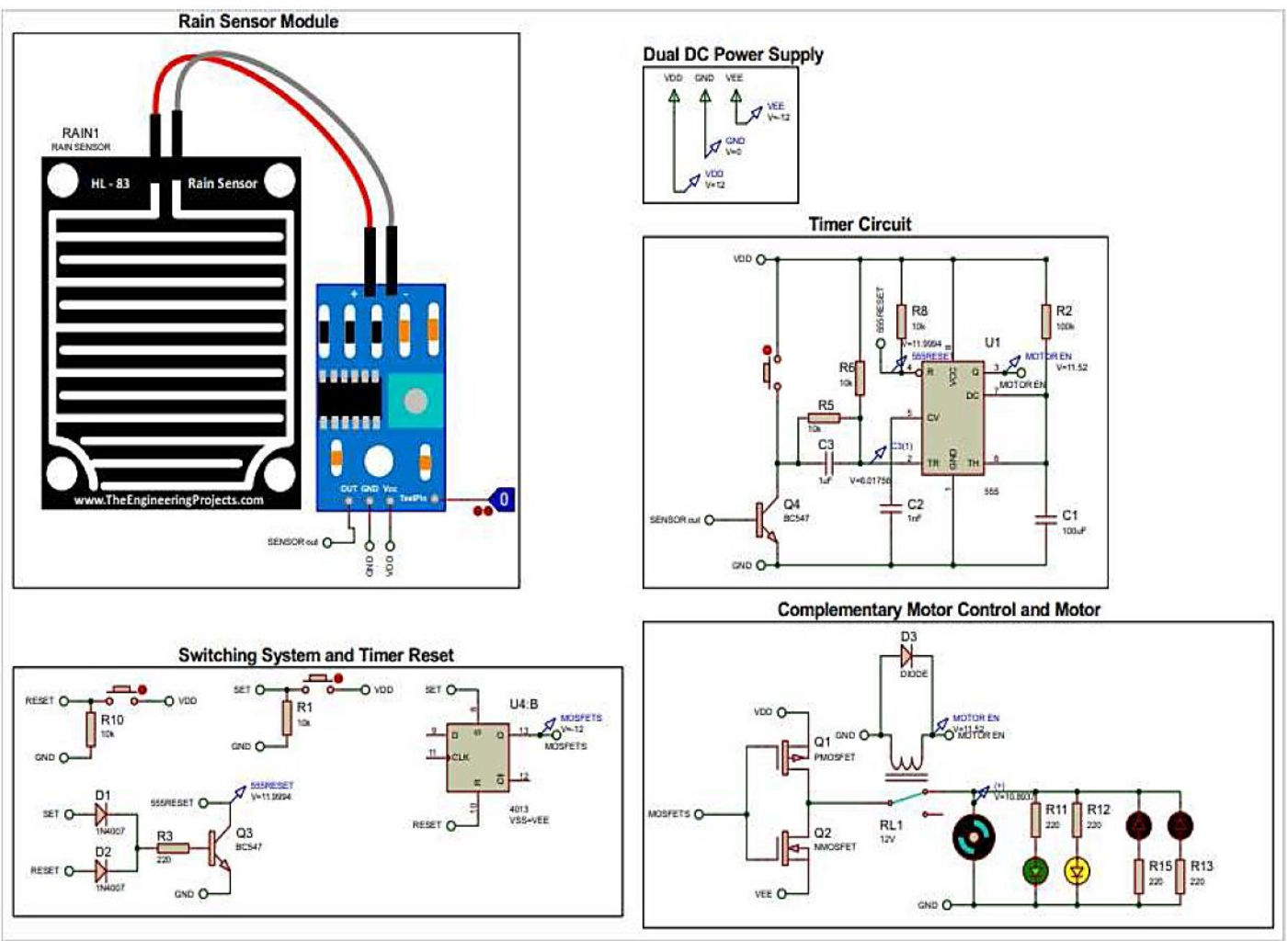

Figure 3: Complete circuit diagram of the AARCSCS 


\section{RESULTS AND DISCUSSION}

\section{i. When it rains}

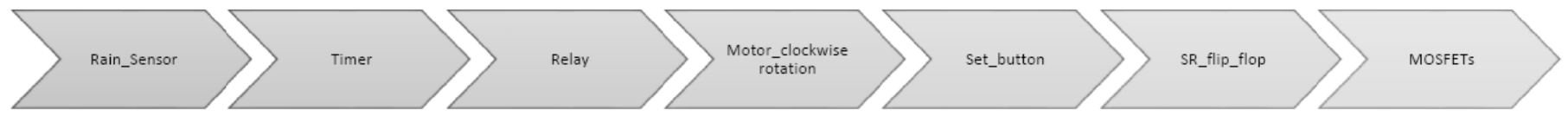

The rain falls on the sensor (blackish part) and activates sensor output to go high, and a signal is sent to the timer. The output of the sensor turns on the BC547, BJT, which triggers the timer to switch $\mathrm{ON}$ in a monostable state and outputs high voltage via pin 3, which is the input to the relay (MOTOR EN). This switches contacts and connects the MOSFETs to the motor circuit. The motor is turned ON by PMOSFET that is activated by the default low state, rotates in the clockwise direction, and the yellow and green LEDs light. An interfacing mechanism of the trenchcover mechanism is assumed to press the SET switch. Pressing the SET button does two things; First, switch the timer OFF, thereby demagnetize the relay solenoid hence switch contacts that power the motor. Secondly, set the SR flip flop and thereby setting the MOSFETs to a high.

\section{ii. After it rains}

The rain sensor remains high due to raindrops on it. To reverse the motor after it has stopped raining;

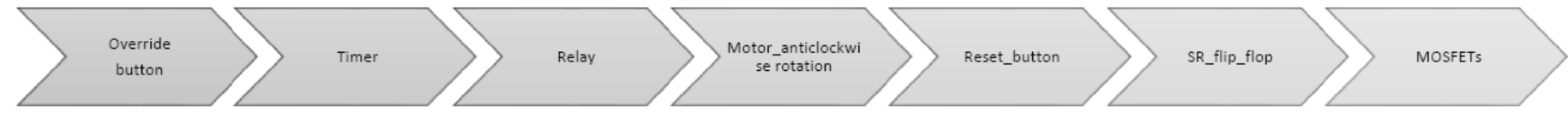

When the Override button is pressed, it triggers the timer the same way as the sensor. The timer powers the solenoid of the relay, thereby switching contacts to connect the motor to the MOSFETs, thus current flows. The motor rotates anticlockwise due to the previous set state, which was "a high", operated by the activated NMOSFET. The red and yellow LEDs light. When the reset switch is pressed, this switches OFF the timer, ultimately breaking contact and turning OFF the motor. The latter also sets the SR flip flop to a low, which is the input to the MOSFETs, for running the motor when the contact is closed by the relay.

The designed system was also tested for the capability to perform critical functions as intended. Different sub-sections were scrutinized in Proteus to determine its ability to meet the design requirements

\section{(i) Motor Rotation}

For the system to fulfill its task of driving the trench-cover mechanism to extend or retract, the motor had to be able to rotate clockwise and anticlockwise. The requirement was tested by supplying the motor with a $12 \mathrm{~V}$ supply for each instance of rotation.

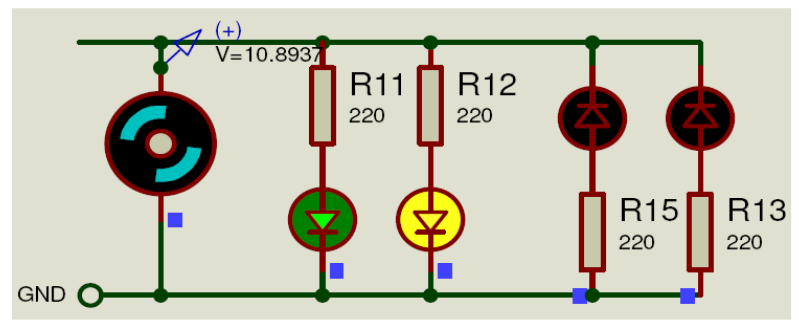

Figure 4: Clockwise rotation



Figure 5: Anticlockwise rotation

Fig 4 shows that the motor was able to rotate clockwise but not at the target voltage. Fig 5 shows that the motor was able to rotate anticlockwise, approximately at the target voltage. The two figures indicate that the goal of motor direction control is achieved though not at the target voltage, which lowered the power generated by the motor.

(ii) Timed Power Supply

The design was able to run the motor for a predetermined amount of time by using a 555 timer to turn on a relay which closes the contacts for the motor to run. The requirement was tested by triggering the timer and observing if the motor would run and stop without using the reset or set pin.

The motor was able to run for $11.3 \mathrm{~s}$ (approx. $11 \mathrm{~s}$ due to human reaction time to pause simulation), as shown in Fig 6. The design had approximately fulfilled the target value. 


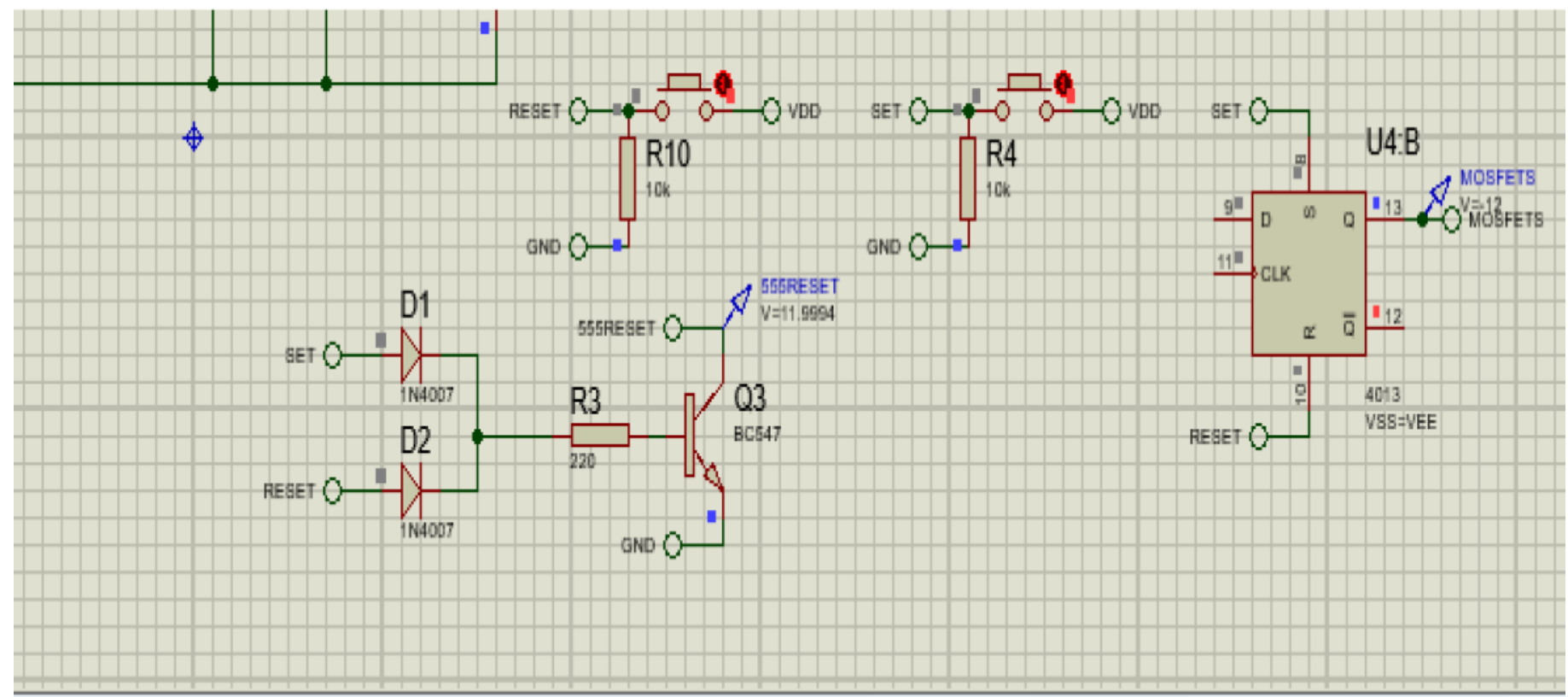

\section{PAUSED: 00:00:11.381343}

Figure 6: Power supply time by 555 timer

(iii) Timer Override

One of the measures put in place for energy conservation and motor protection is the feature of using the SET and RESET switch buttons to reset the timer when the trenchcover mechanism has completed a cycle.

This requirement was tested by running the simulation and pressing the set button to observe if the timer voltage output would fall to zero. The whole activity had to be done within the
11 seconds operation time of the timer. Fig 7 and Fig 8 show the voltage of the output pin 3 of the 555-timer.

From Fig 7, the timer outputs a high voltage, at 5 seconds since no switch has been pressed yet. The set switch button is pressed at 7 seconds, and the timer outputs a low as shown in Fig 8. The target voltage was met precisely.

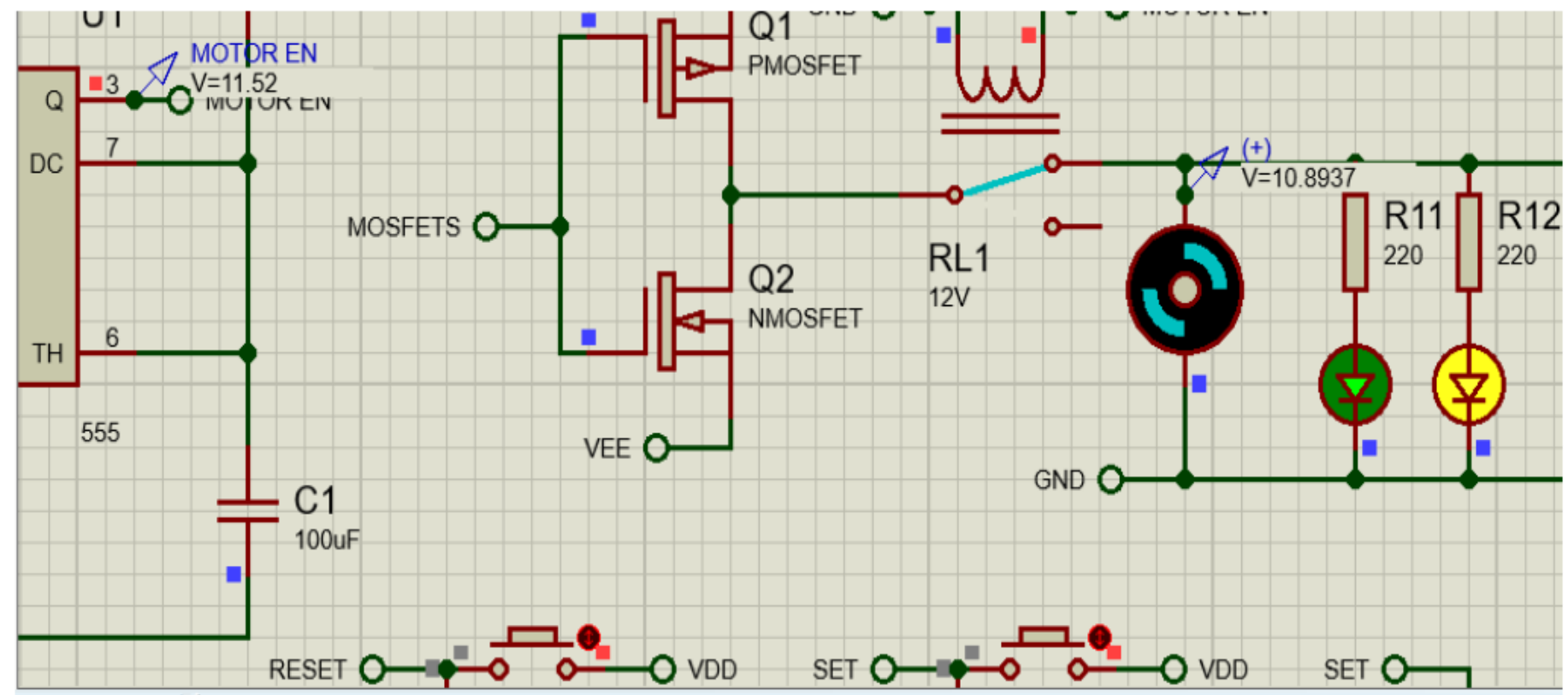

(1) 5 Message(s) PAUSED: 00:00:05.062534

Figure 7: Voltage of timer high 


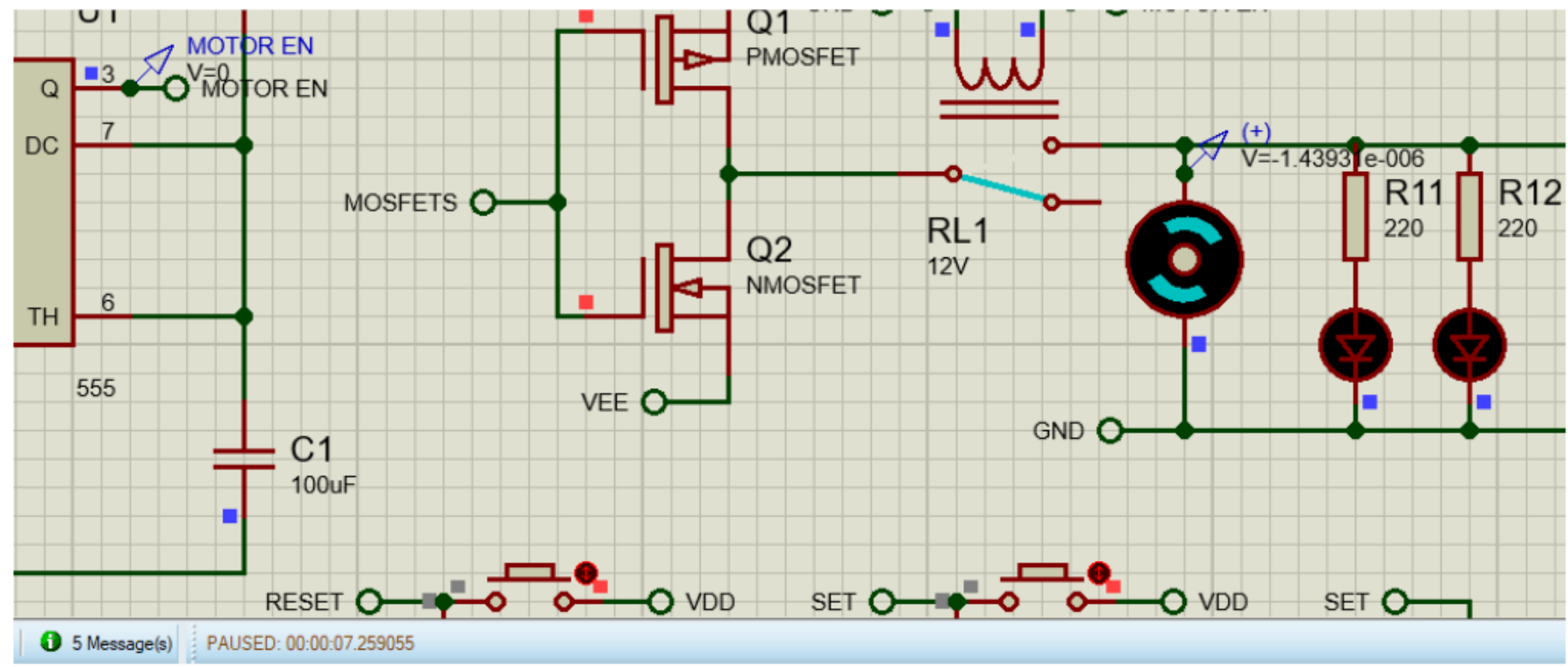

Figure 8: Voltage of timer low

(iv) System Override

After rainfall, the mechanism remains closed while the sensor output also remains at a high due to the residue of raindrops on the sensor. The user should be able to override the sensor functionality by pressing the override button for the trenchcover mechanism to be powered $\mathrm{ON}$ again but running in the opposite direction. The requirement was tested by holding the sensor test pin at high and pressing the override button to see if the system would run again in the reverse direction. Fig 9 and Fig 10 shows the direction in which the motor is turning before and after pressing the override button.

In Fig 9, the motor ran forward as seen by the LED lights when the sensor output was high, it ran until the set switch was pressed. In Fig 10, the override button was pressed while the sensor output was still at a high, and this caused the motor to run in the opposite direction as indicated by the LEDs.The design fulfilled the desired task.

Table 1 shows a summary of the tests that were carried out on the system.

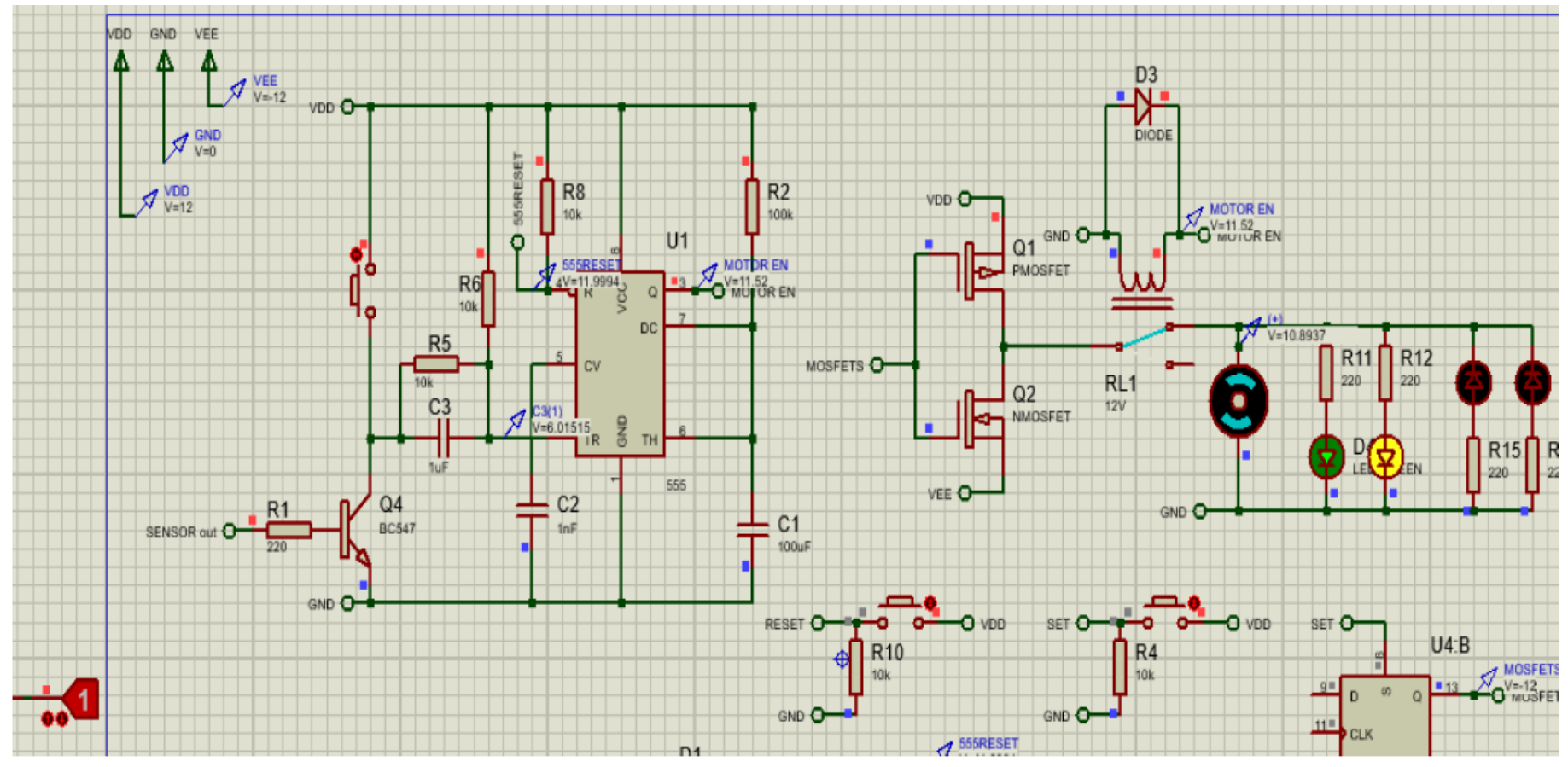

Figure 9: Before pressing Override 


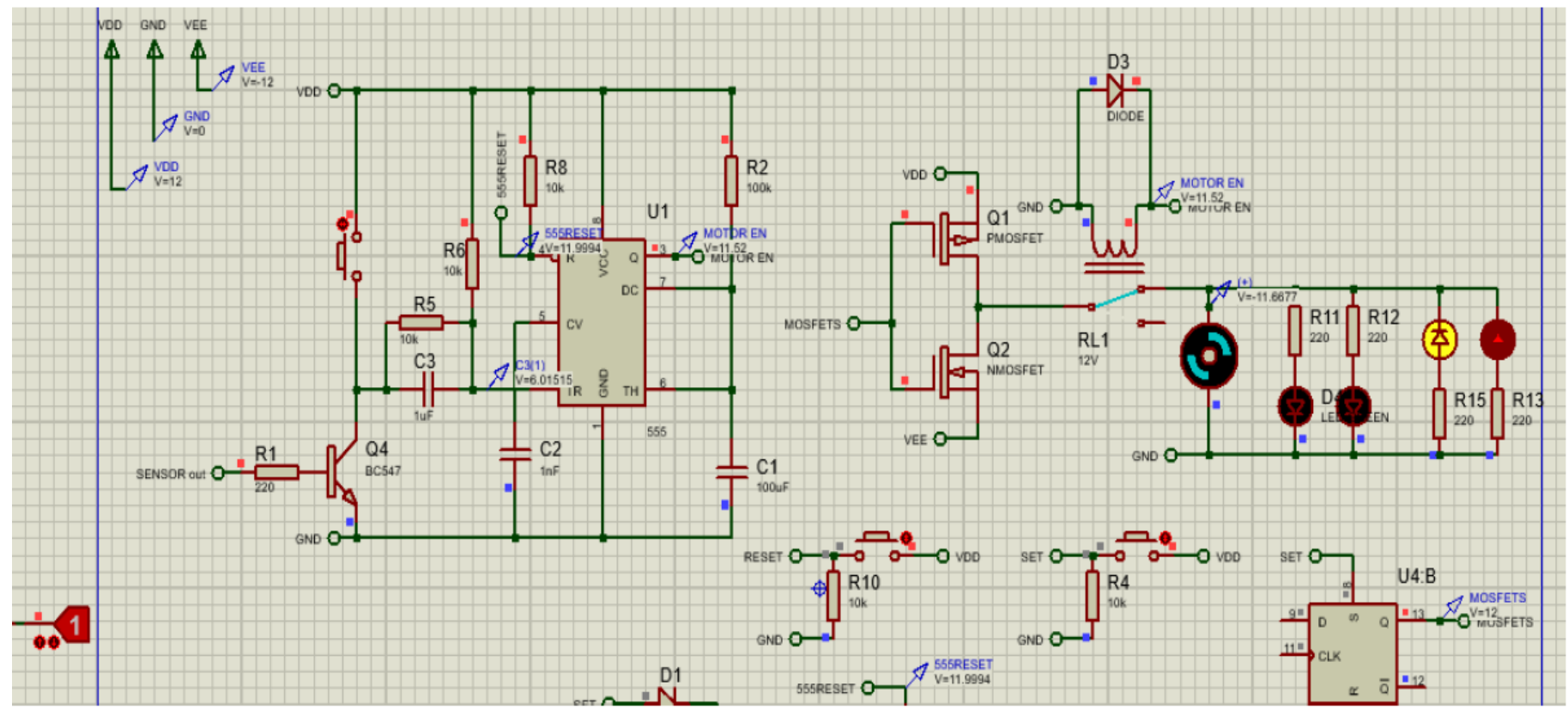

Figure 10: After pressing Override

Table 1: Summary of system tests.

\begin{tabular}{|c|c|c|c|c|}
\hline Requirement & $\begin{array}{l}\text { Target } \\
\text { Value }\end{array}$ & Test Result & $\begin{array}{l}\text { Percent } \\
\text { Achievement } \\
(\%)\end{array}$ & Test Method \\
\hline $\begin{array}{l}\text { Motor clockwise } \\
\text { rotation }\end{array}$ & $12 \mathrm{~V}$ & 10.9 & 90.8 & $\begin{array}{l}\text { Close contact by } \\
\text { relay }\end{array}$ \\
\hline $\begin{array}{l}\text { Motor } \\
\text { anticlockwise } \\
\text { rotation }\end{array}$ & $-12 \mathrm{~V}$ & -11.7 & 98 & $\begin{array}{l}\text { Close contact by } \\
\text { relay }\end{array}$ \\
\hline $\begin{array}{l}\text { Timed } \quad \text { Power } \\
\text { Supply }\end{array}$ & 11 seconds & 11.5 seconds & $\begin{array}{l}105 \text { (sensible as } \\
95 \text { ) }\end{array}$ & Trigger timer \\
\hline Timer Override & $0 \mathrm{~V}$ & $0 \mathrm{~V}$ & 100 & $\begin{array}{ll}\text { Press SET and } \\
\text { RESET } \\
\text { button }\end{array}$ \\
\hline System Override & $\begin{array}{l}\text { Motor } \\
\text { reverse }\end{array}$ & $\begin{array}{l}\text { Motor } \\
\text { reverse }\end{array}$ & 100 & $\begin{array}{l}\text { Press the Override } \\
\text { push button }\end{array}$ \\
\hline
\end{tabular}

Sample Calculation $\left|\frac{10.9}{12}\right| \times 100 \%=90.8 \%$

\section{CONCLUSION}

In this work, the design, simulation, and analysis of the Autonomous Anti-Rain Construction Site Cover System is presented. The main focus was to design the circuit that would power and control a specifically designed trench-cover mechanism to cover the trenches when there is rainfall. The systems circuit was designed and simulated in Proteus. During the simulation process, the various requirements of the circuit were tested and the results were summarised in Table 1. Based on the results, as shown in Table 1, the system has achieved the intended requirements. The system is capable of controlling the direction in which a motor turns to demonstrate the ability to sense rain and run the motor forward, which indicates that the trench-cover mechanism would be extended successfully without any human input. The design also allows for uncovering of the trench when it stops raining as done by the override button. The system interfaced with an appropriate trench-cover mechanism that can be utilized by contractors to prevent flooding of trenches and ultimately mitigate problems associated with it, such as increased operational costs, hazards to workers, and compromised project time frame. 


\section{REFERENCES}

[1] S. Zhao, L. Du and X. Chen, "The related problems in the construction of the rainy season," pp. 28-35, 2018.

[2] Steven, "How does wet weather affect construction," 19 July 2017. [Online].

Available:https://www.planswift.com/blog/wetweatheraffectconstruction/\#: :text=Wet $\% 20$ weather $\% 20$ can $\% 2$ 0be $\% 20$ a,drivers $\% 20$ of $\% 20$ vehicles $\% 20$ and $\% 20$ equipm ent.

[3] Anon, "Drilling and excavation blog,"10 December 2018. [Online].

Available:https://lassiterexcavating.com/blog/excavating -and-drilling-inwetweather/\#: :text=Soak\%20gallons \%20of\%20water\% 20into,(which\%20is\%20now\%20mud.).

[4] Juan Rodriguez, "The balance small business," 6 December 2019. [Online].

Available:https://www.thebalancesmb.com/what-isdewatering-844520. [Accessed 19 July 2020].

[5] Admin, "Tips for managing construction project during rainy season," Murrow Construction Oversight Consultants, 27 October 2017. [Online]. Available:http://murowcm.com/tipsmanagingconstruction-projects-rainy-season/. [Accessed 19 July 2020].

[6] A. J. Martinez, "Analysis of Job-sites in San Luis Obispo County Adapting to Unforeseen Wet Conditions," San Obispo, 2019.

[7] "BIUST," Botwana International University of Scienece and Technology, 2020.[Online].Available: https://www.bi ust.ac.bw/about-us/history/. [Accessed 21 August 2020].

[8] K. Anshumali and S. Bhattacharya, "Automatic Rain Sensing Vehicle Wiper," vol. 7, no. 2, p. 11, 2019.

[9] N. Nandanavanam, "An Imprint of IC555 Timer in the Contemporary," vol. 4, no. 6, pp. 1-2, 2015.

[10] A. Murtala, K. Jonathan and O. Ijarotimi, "A Simple and Reliable Touch Sensitive Security System," p. 7, 2012.

[11] M. Ahmed, A. Sheir and M. Orabi, "Asymmetric cascaded half-bridge multilevel inverter," vol. 57, no. 4, p.2416, 2018.

[12] S. Kivrak, M. Z. Erel, Y. Yalman and K. C.Bayindir,"Design and Implementation of the Three Phase H-bridge Motor Drive Controlled by two DC Motors using PID controller," in MECHANIKA 2017, Turkey, 2017.

[13] R. Ali, I. Daut, S. Taib, N. S. Jamoshid and A. R. A. Razak, "Design of highside MOSFET driver using discrete components for $24 \mathrm{~V}$ operation," in Power Engineering and Optimization Conference (PEOCO), $20104^{\text {th }}$ International, Malaysia, 2010.

[14] "Electronics Tutorials," AspenCore, 2020. [Online].Available:https://www.electronicstutorials.ws/transistor/tran_7.html. [Accessed 27 August 2020].

[15] O.Samson, S.Olawale and A. Emmanuel, "Circuit Enhancements of Set and Reset Flip Flops," vol. 53, no. 77 , p. 5, 2019. 